McGuigan and K.L. Pittam who performed the insulin tolerance tests. Dr. G. C. Wells, Dr. M. M. Black, Dr. I. W. Whimster, and Dr. P. F. D. Naylor provided essential criticism in the preparation of this paper.

\section{References}

${ }^{1}$ Sneddon, I. B., Bulletin de la Société Française de Dermatologie et de Syphiligraphie, 1970, 77, 670.

2 Feiwel, M., British fournal of Dermatology, 1969, 81, Suppl. 4, 113.

3 Burton, J. L., et al., British fournal of Dermatology, 1974, 91, Suppl. 10, 22.

${ }^{4}$ Munro, D. D., Feiwel, M., and James, V. H. T., in Proceedings of the XIII Congressus Internationalis Dermatologiae, ed. W. Jadassohn and C. G. Schirren, p. 202. Berlin, Springer, 1968.
5 James, V. H. T., Munro, D. D., and Feiwel, M., Lancet. 1967, 2, 1059. Scoggins, R. B., and Kliman, B., New England fournal of Medicine, 1965, 273, 831 .

7 Feldman, R. V., and Maibach, H. I., in Proceedings of the XIII Congressus Internationalis Dermatologiae, ed. W. Jadassohn and C. G. Schirren, p. 186. Berlin, Springer, 1968.

${ }^{8}$ Sparkes, C. G., and Wilson, L., British fournal of Dermatology, 1974, 90, 197.

9 Walker, S. R., et al., British Fournal of Dermatology, 1974, 91, 339.

Murphy, B. E. P., Fournal of Clinical Endocrinology and Metubolism, $1967,27,973$.

11 Landon, J., Wynn, V., and James, V. H. T., Fournal of Endocrinology, $1963,27,183$.

12 Tan, R. S. H., and Samman, P. D., Proceedings of the Royal Society of Medicine, 1974, 67, 719.

13 Baker, H., and Ryan, T. J., British Fournal of Dermatology, 1968, 80, 771. Munro, D. D., and Clift, D. C., British fournal of Dermatology, 1973, 88,

15 Hendrikse, J. C. M., and Moolenaar, A. J., Dermatologica, 1972, 144, 179.

\title{
Removal of Abnormal Clone of Leukaemic Cells by Splenectomy
}

\author{
G. GOMEZ, D. K. HOSSFELD, J. E. SOKAL
}

British Medical fournal, 1975, 2, 421-423

\section{Summary}

A patient with chronic myelocytic leukaemia positive for the Philadelphia $\left(\mathbf{P h}^{1}\right)$ chromosome underwent splenectomy in the "terminal phase" of his disease. Chromosomal analysis of a marrow aspirate obtained during the operation showed nothing abnormal. Material from the spleen, however, showed the absence of a $C$ chromosome and the presence of a "marker" chromosome in all metaphases examined. The patient did well for almost three years after splenectomy, and serial cytogenetic studies of marrow specimens showed the $\mathbf{P h}^{1}$ chromosome to be the only significant abnormality. Six months before death from recurrent blastic transformation aneuploidy was found in a marrow specimen. Subsequently additional abnormalities, including cells with two $\mathbf{P h}^{1}$ chromosomes, were detected. The karyotypic abnormalities found in the splenic specimen, however, never recurred.

\section{Introduction}

Chronic myelocytic leukaemia (C.M.L.) is usually characterized by the Philadelphia $\left(\mathrm{Ph}^{1}\right)$ chromosome in cells of myeloid origin. With rare exceptions ${ }^{1}$ this is a constant feature, being found in overt disease, during excellent clinical and haematological remissions, and in the terminal stages. $\mathrm{Ph}^{1}$-positive cells may become established in the spleen ${ }^{2} 3$ and other extramedullary sites. ${ }^{4}$

In some patients the $\mathrm{Ph}^{1}$ chromosome is the only karyotypic abnormality detectable throughout the course of the disease. Additional cytogenic abnormalities, however, may appear as the patient enters the terminal stage. These include changes in the number of chromosomes, the appearance of "marker" chromosomes, and the presence of cells containing two $\mathrm{Ph}^{1}$ chromo-

Roswell Park Memorial Institute, New York State Department of Health, Buffalo, New York, 14263

G. GOMEZ, M.D., Cancer Research Internist
D. K. HOSSFELD, M.D., Visiting Scientist (Present address: Department of Medicine, University of Essen, West Germany)

J. E. SOKAL, M.D., Chief Cancer Research Internist 
remained below $5 \%$. On 24 September the spleen extended $21 \mathrm{~cm}$ below the costal margin, the W.B.C. was $129 \times 10^{\circ} / 1$ (2\% blasts, $3 \%$ promyelocytes), and the platelets were $32 \times 10^{\%} / 1$. A bone marrow aspirate was reported as showing "early myeloblastic transformation" (blasts $15.4 \%$, promyelocytes $21.6 \%$ ) and the patient was referred to us. He was given loading doses of hydroxyurea $(0.05 \mathrm{~g} /$ $\mathrm{kg}$ ) to control the rising W.B.C., and on 29 September splenectomy was performed. The spleen (which had decreased in size with hydroxyurea) weighed $1800 \mathrm{~g}$ and contained many immature myeloid cells and a few normoblasts but no megakaryocytes. The postoperative course was uneventful and the platelet count rose to over $200 \times 10^{\%} / 1$.

The patient was then treated with a demecolcine-mercaptopurine combination $^{7}$ and entered an immunotherapy programme for C.M.L. ${ }^{8}$ An excellent remission was achieved and he remained in a good haematological and clinical condition for almost three years in a programme of "rotating" maintenance chemotherapy with two-drug combinations. In June 1973 routine bone marrow aspiration showed aneuploidy but an otherwise normal marrow. Five weeks later immature cells were detected in the peripheral blood and bone marrow aspiration showed $17.6 \%$ myeloblasts. His haematological and clinical condition deteriorated rapidly, with anaemia, thrombocytopenia, fever, subcutaneous nodules, and bone pain. He responded poorly to various antileukaemic agents and died on 12 December. Necropsy showed pseudomonal bronchopneumonia and extensive leukaemic infiltration of viscera and lymph nodes.

\section{CHROMOSOMAL STUDIES}

Chromosomal studies (direct method) of marrow were performed on nine occasions. In conjunction with splenectomy (29 September 1970) chromosomal analyses were performed on both a bone marrow aspirate (obtained at operation) and material from the spleen. The table gives the findings of cytological and chromosomal examinations of the marrow and spleen during the illness. Before splenectomy marrow aspirates usually showed florid leukaemia. This was presumably because thrombocytopenia prevented the use of enough chemotherapy

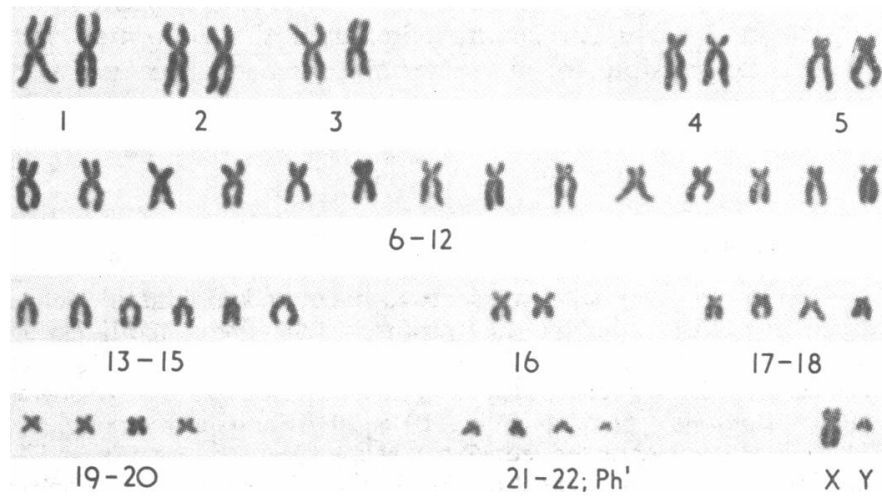

FIG. 1-Typical karyotype from bone marrow aspirate obtained at splenectomy. to achieve better control of the disease. Nevertheless, the percentage of myeloblasts was normal until 24 September 1970. Chromosomal studies showed no abnormalities other than the presence of a single $\mathrm{Ph}^{1}$ chromosome.

On 29 September the bone marrow showed unequivocal improvement after chemotherapy with an agent not previously used. Chromosomal analysis of the marrow aspirate showed no appreciable change from previous studies (fig. 1). The splenic karyotype, however, was grossly abnormal. All 22 mitoses examined contained a submetacentric marker chromosome replacing a chromosome of group C (6-12). In addition some mitoses contained an abnormality of the second G-22 chromosome, which appeared as a smudge (fig. 2).
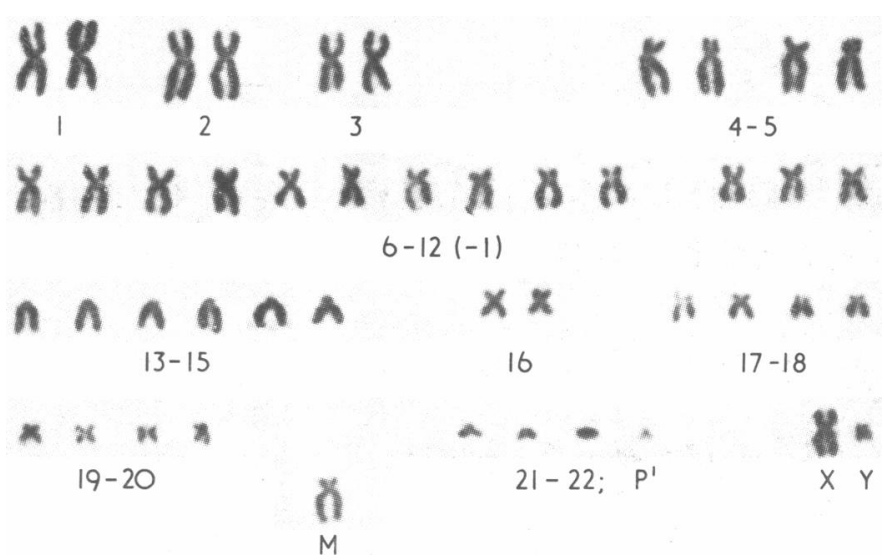

FIG. 2-Karyotype from spleen showing missing C-group chromosome marker chromosome (M), and "smudged" G-22 chromosome.

These karyotypic abnormalities were never seen again. On 29 June 1973, when haematological values were consistent with complete remission, aneuploidy was observed in all metaphases. On 6 August nine out of 11 cells examined contained 51 chromosomes including two $\mathrm{Ph}^{1}$ chromosomes.

\section{Discussion}

These findings are consistent with the hypothesis that (a) a grossly abnormal clone of leukaemic cells originated and was proliferating in the spleen, while less abnormal cells were multiplying in the marrow; $(b)$ the abnormal clone was eliminated by splenectomy; and $(c)$ combination chemotherapy and immunotherapy resulted in a prolonged remission once the more malignant clone of cells had been removed.

Unfortunately karyotypic analysis was not carried out in conjunction with marrow aspiration on 24 September 1970, when a sharp increase in the percentage of myeloblasts was recorded.

Marrow Cytology and Chromosomal Analyses

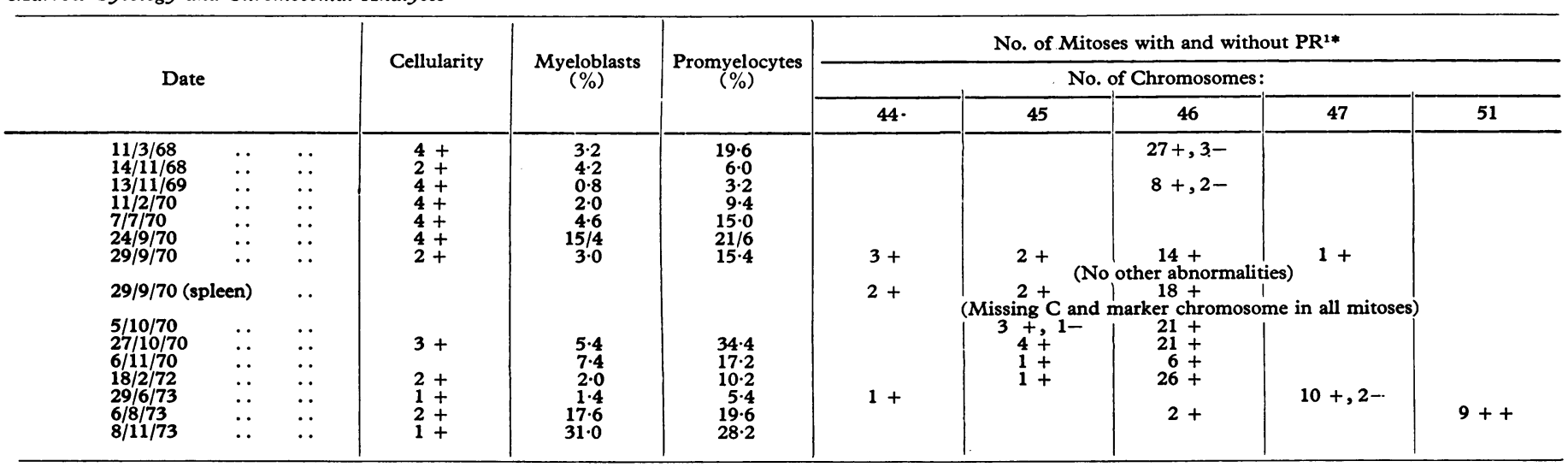

+ + = Single $\mathbf{P h}^{1} .++=$ Double $\mathrm{Ph}^{1} .-$ = No $\mathrm{Ph}^{1}$ seen. 
Possibly these may have been of splenic origin, containing the abnormal karyotype, and were eliminated by the brief but effective course of hydroxyurea before splenectomy. If so, one would assume that the marrow had not then been colonized by the abnormal clone. It appears highly unlikely that so short a course of hydroxyurea would have had a permanent effect on an established population of cells in marrow while leaving the splenic clone easily demonstrable. Large numbers of neoplastic cells may enter the marrow from other sites without establishing a proliferating population there. We have seen four patients with disseminated lymphoproliferative disease ${ }^{9}$ and one with "blastic" myeloid metaplasia of the spleen (unpublished data) in whom marrow remission followed local radiation therapy or splenectomy.

Aggressive treatment of myeloblastic transformation may temporarily eliminate clones of leukaemic cells with karyotypic abnormalities, ${ }^{10}$ but such remissions are usually short-lived and the abnormal karyotype often recurs within weeks. ${ }^{11}$ In our patient, in contrast, the abnormal clone of cells shown in the spleen disappeared permanently after splenectomy. Karyotypic abnormalities were again found during the last six months of life, but these were different from those seen originally. Nevertheless, cytogenetic examination on 29 June 1973, when the patient appeared to be in complete remission of leukaemia, predicted the rapid haematological and clinical deterioration that was observed a few weeks later.

Attempts to reverse the terminal episode of myeloblastic transformation were unsuccessful. This is consistent with our experience that $\mathrm{Ph}^{1}$-positive patients who develop additional karyotypic abnormalities are much more refractory to treatment

\section{SHORT REPORTS}

\section{Q Fever Presenting with Paroxysmal Ventricular Tachycardia}

A description of myocarditis complicating $Q$ fever ${ }^{1}$ prompts us to report a patient who presented with recurrent ventricular tachycardia and was found to have $Q$ fever.

\section{Case History}

A 51-year-old insurance company manager, who occasionally visited farms, became febrile and had several rigors 10 days before admission. Two days after these, after some dizziness, he briefly lost consciousness. Over the after these, after some dizziness, he briefly lost consciousness. Over the similar syncopal attacks. He looked pale and unwell and his pulse was 52 similar syncopal attacks. He looked pale and unwell and his pulse was 52
and irregular. The only other abnormality was a localized area of coarse and irregular. The only other abnormality was a localized area of coarse crepitations at the left lung base. Blood pressure was 140/70. There was no evidence of congestive cardiac failure or endocarditis. E.C.G.s (see figure) showed frequent premature ventricular ectopic beats, paroxysmal ventricular
tachycardia, and ST-T wave changes; haemoglobin was $13.1 \mathrm{~g} / \mathrm{dl}$; W.B.C. tachycardia, and ST-T wave changes; haemoglobin was $13 \cdot 1 \mathrm{~g} / \mathrm{dl}$; W.B.C. $7.6 \times 10^{9} / 1$, with normal differential count; E.S.R. $70 \mathrm{~mm} / \mathrm{hr} ;$ S.G.O.T. 34 units; blood cultures sterile. Chest $x$-ray film showed a small area of burnetti titres were: $<8,1024,2048$ on days 1,21 , and 33 , respectively. A provisional diagnosis of viral myocarditis was made. The arrhythmia was difficult to control; it was treated initially with lignocaine and later with several combinations of other anti-arrhythmic drugs, including phenytoin, procainamide, and practolol, but was not fully controlled until 10 days later. He also had tetracycline for bu weeks. The syntrolled until 10 days later. to vonicis attributed to months was completely well.

\section{Discussion}

Though ventricular ectopic beats may occur with any febrile illness, the nature, duration, and severity of this arrhythmia and the associated of the blastic state than patients who retain the original chromosomal pattern.

We have carried out simultaneous karyotypic analysis of spleen and marrow aspirates from five other patients undergoing splenectomy during the accelerated or blastic phase of the disease but have not identified other instances of such cytogenetic discordance. From our experience, which includes 30 patients subjected to splenectomy during the "terminal phase" of C.M.L., such gratifying responses are unusual. The present case, however, is probably not unique. Our series includes two other patients whose disease reverted to an easily controlled chronic state and who survived more than three years after splenectomy. Unfortunately, both were treated before we initiated chromosomal studies of splenic cells.

\section{References}

1 Dowling, M. D., et al., Proceedings of the American Association for Cancer Research and American Society of Clinical Oncology, 1974, 15, 189.

2 Spiers, A. S. D., and Baikie, A. G., Nature, 1965, 208, 497.

3 Hossfeld, D. K., and Schmidt, C. G., in Chemotherapy of Cancer Dissemination and Metastasis, ed. S. Garattini and G. Franchi, p. 223. New York, Raven Press, 1973.

4 Duvall, C., et al., Blood, 1967, 29, 652.

Lawler, S. D., and Galton, D. A. G., Acta Medica Scandinavica, 1966, Suppl. No. 445 , p. 312.

6 Whang-Peng, J., et al., Blood, 1968, 32, 755.

Sokal, J. E., and Aungst, C. W., Proceedings of the American Association for Cancer Research, 1970, 11, 74

${ }^{8}$ Sokal, J. E., Aungst, C. W., and Grace, J. T., jun., National Cancer Institute Monograph, 1973, 39, 195.

${ }^{9}$ Han, T., Ezdinli, E. Z., and Sokal, J. E., Cancer (Philadelphia), 1967, 20, 243.

10 Garson, O. M., Burgess, M. A., and Stanley, L. G., British Medical Fournal, 1969, 2, 556 .

11 Canellos, G., et al., Blood, 1971, 38, 671.

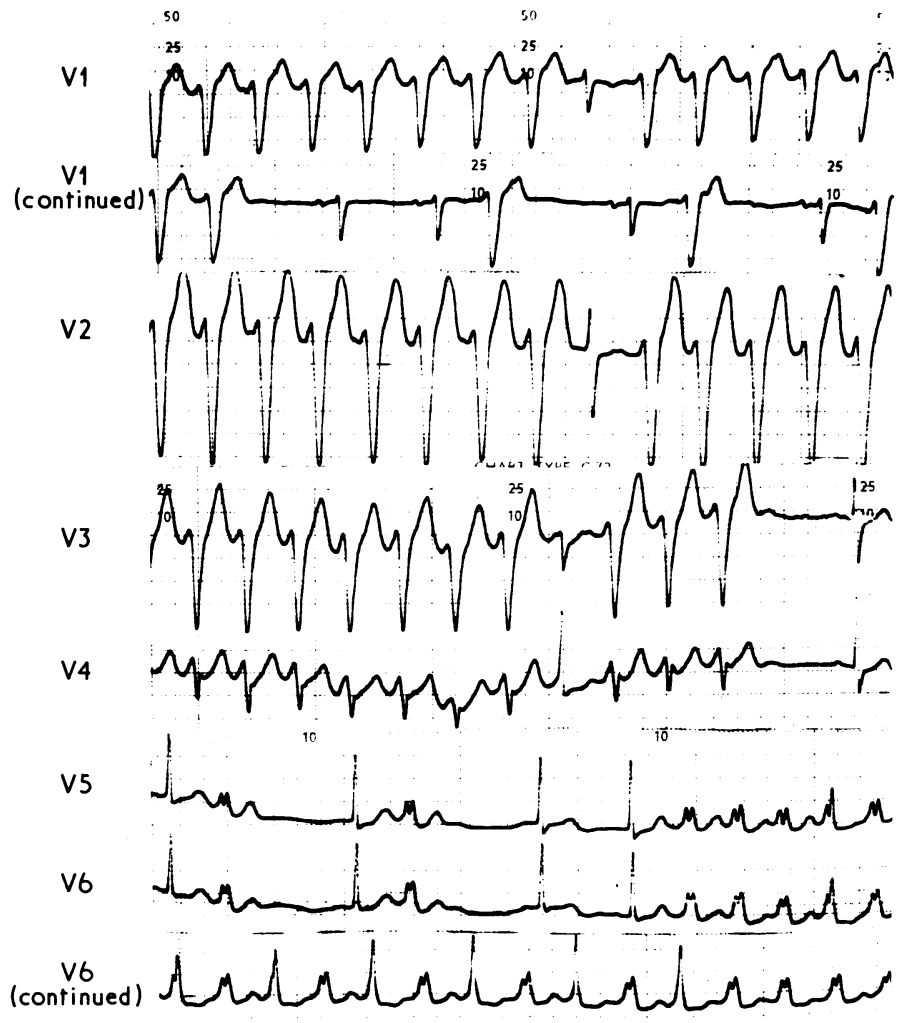

E.C.G. showing premature ventricular ectopic beats, paroxysmal ventricular tachycardia, and ST-T wave changes. 